\title{
Patient or Clinician: Duration of Use of Intrauterine Devices Based on Who Initiated Discussion of Placement
}

\author{
Tammy Chang, MD, MPH, MS, Michelle H. Moniz, MD, MSc, Melissa A. Plegue, MA, \\ Kathryn Sage Shaffer, MD, Heather B. Vance, MD, and Katherine J. Gold, MD, MSW, MS
}

Background: Although safe and effective, intrauterine devices (IUDs) are underutilized in the United States. The objective of this study was to determine whether patient- and clinician-initiated discussions were associated with the duration of Mirena $(52 \mathrm{mg}$ levonorgestrel-releasing) IUD use.

Methods: Retrospective chart review identified Mirena IUDs that were placed and removed for reasons other than the desire for pregnancy from January 1, 2005, to January 1, 2012, at 1 academic center $(n=148)$. Multivariable linear regression examined the independent association between duration of use and source of discussion initiation.

Results: IUDs placed after patient-initiated discussions were used for $\mathbf{4 7 3}$ days longer than those placed after clinician-initiated discussions $(P<.001)$.

Conclusion: Patient-initiated discussions of Mirena IUDs are associated with a significantly longer duration of use. Patient influences outside the clinical encounter may be important in optimizing use. (J Am Board Fam Med 2016;29:24-28.)

Keywords: Intrauterine Devices, Physician-Patient Relations, Social Networks

Despite being safe and highly effective, intrauterine devices (IUDs) are used by less than $6 \%$ of women who use contraception in the United States. ${ }^{1-3}$ Furthermore, up to $30 \%$ of IUDs are removed within 1 year of placement, which diminishes cost-effec-

This article was externally peer reviewed.

Submitted 10 June 2015; revised 16 September 2015; accepted 25 September 2015.

From the Department of Family Medicine (TC, MAP, KJG), the Institute for Health Policy and Innovation (TC, MHM), Department of Obstetrics \& Gynecology (MHM, $\mathrm{KJG}$ ), and the Robert Wood Johnson Foundation Clinical Scholars Program (MHM), the University of Michigan, Ann Arbor; the Providence Family Medicine Residency, Southfield, MI (KSS); and the Department of Family Medicine, Boulder Medical Center, Boulder, CO (HBV).

Funding: MM was funded by the Robert Wood Johnson Foundation Clinical Scholars Program during the period of data analysis and manuscript preparation.

Prior presentation: The work was presented at the annual meeting of the Society of Teachers of Family Medicine, San Antonio, TX (May 3-7, 2014); and at the Academy Health Annual Research Meeting, San Diego, CA (June 8-10, 2014).

Conflict of interest: none declared.

Corresponding author: Tammy Chang, MD, MPH, MS, University of Michigan, Department of Family Medicine, 1018 Fuller Street, Ann Arbor, MI 48104 (E-mail: tachang@med.umich.edu). tiveness and creates gaps in contraceptive coverage that can increase risk for unplanned pregnancy. ${ }^{4}$

Current clinical practice depends on clinician counseling to encourage IUD use. ${ }^{5}$ However, patients initiating the discussion could represent increased patient engagement in contraceptive decision making that could affect commitment to the method. Studies have demonstrated that soliciting patients' needs and preferences, involving family members, and tailoring education engender greater patient satisfaction and adherence and improved patient outcomes. ${ }^{6}$ The aim of this study was to determine whether patients who desired contraception used IUDs longer if they-rather than the clinician-were the ones to request this method.

\section{Methods \\ Data Collection}

Retrospective chart review identified all women with billing codes for both placement and removal of a Mirena IUD in a 7-year period (January 1, 2005, to January 1, 2012) at a large Midwestern academic institution. This includes women seen at primary care and specialty clinics, as well as patients 
seen by both resident and attending providers. Mirena IUDs were the focus of this study because they are the more popular type of IUD and because levonorgestrel and copper IUDs are distinct with regard to side effects, noncontraceptive benefits, maximal duration of use ( 5 vs 10 years), and reasons patients decide to initiate each method. Data were extracted on age, race/ethnicity, insurance type, reason for removal, and dates of placement and removal. Reasons for removal included abdominal pain, malposition, ovarian cyst, mood lability, bloating, irregular bleeding, infection (pelvic inflammatory disease), and partner discomfort; charts could be coded with multiple reasons for removal. Duration of IUD use was the time (days) between IUD placement and removal. Cases were excluded if the IUD was discontinued because of a desire for pregnancy or inadvertent device expulsion; these represent women who no longer desire contraception or had a truncated duration of use that was unrelated to their preference, respectively. The study was approved by the University of Michigan Institutional Review Board.

Two investigators (KSS, TC) independently reviewed all notes written during the 1 year before Mirena IUD placement to reach a consensus on whether the discussion regarding placement was patient-initiated, clinician-initiated, or the source of initiation was indeterminable. Reviewers were blinded to the duration of Mirena IUD use. Agreement between the 2 investigators was $93 \%$. Disagreements were reconciled during an in-person meeting where charts were reviewed together to reach consensus. The discussion was characterized as patient-initiated if the medical chart clearly documented that the patient requested an IUD and contained no notes describing any prior birth control counseling that may have influenced that decision. Examples of patient initiation include notes that unambiguously documented that the patient is "requesting an IUD," "has questions about getting an IUD," or "is thinking about an IUD," with no previous visit notes that discuss contraception more broadly. A clinician-initiated discussion was defined as documentation showing that a clinician counseled the patient on the placement of an IUD, often within a broader discussion of contraceptive options. Examples of clinician initiation include notes that discussed discussions of "birth control options," visits for "contraception," or discussions of "family planning" that ultimately resulted in the placement of a Mirena IUD. The source of the discussion was deemed "indeterminable" when there was no note before the placement or if the medical record was otherwise ambiguous regarding who initiated the discussion. For example, if the note described a discussion about contraception, but it was unclear whether the patient or clinician initiated discussion regarding the IUD, it was categorized as indeterminable.

\section{Analysis}

Descriptive statistics, $\chi^{2}$ analyses, and independent sample $t$ tests compared baseline characteristics of the patient-initiated and clinician-initiated IUD placement subgroups and average duration of IUD use. Multivariable linear regression assessed for an association between Mirena IUD duration of use and initiator of discussion, controlling for age, race (non-Hispanic white vs other), and insurance (public vs private) as a proxy for socioeconomic status. Because of the small sample sizes, all other races/ ethnicities (besides non-Hispanic white) were combined into 1 group ("other"). Statistical significance is defined as a $P$ value $<.05$.

\section{Results}

\section{Analytic Sample}

Chart review identified 253 cases of women who had a Mirena IUD both placed and removed at the institution between January 1, 2005, and January 1, 2012. Of these cases, 61 were excluded because of a desire for pregnancy and 3 because of inadvertent device expulsion. Those missing demographics $(\mathrm{n}=1)$ or with an indeterminate initiator $(n=40)$ also were excluded, yielding a final cohort of 148 .

Table 1 outlines sample demographics. The mean duration among patient-initiated IUDs was significantly higher (628 days) than among clinician-initiated IUDs $(159$ days; $P<.001)$. There were no significant demographic differences between the patient- and clinician-initiated IUD groups.

Overall, the average duration of IUD use was 495 days (standard deviation, 553 days). A total of 61 patients removed their IUD before 6 months; the remaining 87 retained their IUD longer than 6 months. Nearly 74\% of clinician-initiated IUDs and only $28 \%$ of patient-initiated IUDs were removed before 6 months. This was signif- 
Table 1. Demographics of Women with Mirena Intrauterine Devices Placed and Removed, 2005-2012

\begin{tabular}{|c|c|c|c|c|}
\hline \multirow[b]{2}{*}{ Variable } & \multicolumn{3}{|c|}{ IUD Use } & \multirow[b]{2}{*}{$P$ Value } \\
\hline & Total $(\mathrm{n}=148)$ & Patient-Initiated $(\mathrm{n}=106)$ & Clinician-Initiated $(\mathrm{n}=42)$ & \\
\hline Race, n (\%) & & & & .709 \\
\hline Non-Hispanic white & $102(69)$ & $74(70)$ & $28(67)$ & \\
\hline Other & $46(31)$ & $32(30)$ & $14(33)$ & \\
\hline Insurance, n (\%) & & & & .246 \\
\hline Public & $46(31)$ & $30(28)$ & $16(38)$ & \\
\hline Private & $102(69)$ & $76(72)$ & $26(62)$ & \\
\hline Age at placement (years), mean (SD) & $31(8)$ & $32(9)$ & $30(8)$ & .137 \\
\hline Duration of use (days), mean (SD) & $495(553)$ & $628(593)$ & $159(179)$ & $<.001$ \\
\hline
\end{tabular}

IUD, intrauterine device; SD, standard deviation.

icant $\left(P<.001, \chi^{2}\right.$ test $)$. Similar results were found for removal before 2 years. Nearly all $(98 \%)$ of the individuals with clinician-initiated IUDs had the IUD removed before 2 years, compared with $72 \%$ of those with patient-initiated IUDs $(P<.001)$.

Multivariable linear regression demonstrated that, after controlling for age, insurance type, and race, IUDs placed after patient-initiated discussions were used, on average, 473 days longer than those placed after clinician-initiated discussions $(P<.001)$. Race was also significantly related to duration: non-Hispanic white women used their IUDs for 231 days longer, on average, than those of other races $(P=.014)$.

The most common reasons for removal of an IUD were irregular bleeding $(\mathrm{n}=66)$ and abdominal pain $(\mathrm{n}=57)$, followed by malposition $(\mathrm{n}=$ 18), bloating ( $\mathrm{n}=11)$, mood lability $(\mathrm{n}=9)$, partner discomfort $(\mathrm{n}=5)$, pelvic inflammatory disease $(n=4)$, and ovarian cysts $(n=3)$. Sensitivity analyses were performed to evaluate the effect of controlling for the reason for removal. However, this variable was not included in our model because no significant differences in duration of use by removal reason were found.

\section{Discussion}

Among women in our sample who desired contraception, Mirena IUDs were used for over 1 year longer if the patient initiated the discussion rather than the clinician. This represents a clinically significant difference in duration of use that potentially contributes to excess cost and risk for unintended pregnancy. To our knowledge, this is the first study to evaluate this variable for duration of
IUD use. With recent health insurance reform affording to millions of women unprecedented access to IUDs, ${ }^{7}$ these findings suggest a need for increased attention to the drivers of patients' contraceptive preferences and method selection. The existing literature describes variation in contraceptive method use by sociodemographic data, satisfaction after placement, or method side effects, but little is known about how patient initiative influences contraceptive decision making and duration of method use. $^{4,8-11}$

Office-based counseling is a potential factor influencing the shorter duration of Mirena IUDs placed after clinician-initiated discussions. Although clinicians often prioritize contraceptive effectiveness and safety, patients may prioritize other features and may highly value autonomy in contraceptive decision making. ${ }^{4,12-15}$ Studies have shown that clinicians may be able to improve contraceptive counseling by interactively engaging women, addressing their fears and misbeliefs about specific methods, and delivering a balanced message about both the benefits and adverse effects of different methods. ${ }^{4,13-15}$

One recent study of $>7000$ women, the Contraceptive CHOICE Project, demonstrated high continuation rates for IUDs and may provide important insight into optimizing the use of IUDs. ${ }^{16}$ Study participants were offered a contraceptive method of their choice with no out-of-pocket expense for up to 5 years. Each participant received standardized, comprehensive contraceptive counseling from trained research staff (most of whom had no formal health care training). Counseling focused on the woman, her expressed needs, situation, problems, issues, and concerns. ${ }^{16,17}$ In this 
setting, IUD acceptance was very high (67\%), and continuation rates were $77 \%$ at 2 years. Further studies are needed to understand how to build on this successful study and optimally engage patients in the clinical setting to identify their preferred contraceptive method.

Our findings also suggest that influences outside of the clinic setting may play an important role in contraceptive decision making. Influence of family, friends, and other sources of information on contraceptive decision making could affect a woman's request for a type of contraception and the probability that she would request an IUD. ${ }^{18}$ These social network resources may be powerful tools that are currently underused to educate patients on birth control options and side effects. ${ }^{19}$ Future studies may want to investigate the effects of facilitating real-life or online interactions with other women who are successfully using IUDs to increase their optimal use.

Despite the novel results, several limitations must be considered. Our sample was drawn from 1 large academic institution and included only women who had a Mirena IUD placed and removed in that institution. Specifically, our sample excluded women whose IUDs were placed between 2005 and 2012 but who did not have a billing code for removal during that time period. For example, a woman who had her IUD placed in 2005 but had it removed at another institution would not be included in our study. In addition, a woman who had her IUD placed in 2011 could potentially still have her IUD in 2016, and she would also not be included in this study. Together these limit the generalizability of our findings to populations in different settings. Although we reviewed medical notes dated up to 1 year before Mirena IUD insertion, notes may not accurately or completely capture all the communication during an office visit, including who initiated the discussion regarding IUD placement. In addition, documentation and counseling may vary by the clinician's amount of training and the patient's level of comfort or familiarity with her provider. However, these factors could not accurately be determined via chart review and thus are not included in this retrospective study. Finally, our study could not identify prior IUD use or differentiate whether an IUD was placed for contraception versus noncontraceptive indications, such as menorrhagia.

\section{Conclusion}

Within our sample, women who initiated the discussion regarding Mirena IUD placement used it for over 1 year longer than women whose clinician initiated the discussion. This is an intriguing finding that could help guide the promotion of IUDs for the prevention of unplanned pregnancy in the United States.

\section{References}

1. Finer LB, Jerman J, Kavanaugh ML. Changes in use of long-acting contraceptive methods in the United States, 2007-2009. Fertil Steril 2012;98:893-7.

2. Trussell J. Contraceptive failure in the United States. Contraception 2011;83:397-404.

3. Jones J, Mosher W, Daniels K. Current contraceptive use in the United States, 2006-2010, and changes in patterns of use since 1995. 2012. Natl Health Stat Report 2012;(60):1-25. Available from: http://www.cdc. gov/nchs/data/nhsr/nhsr060.pdf. Accessed January 27, 2015.

4. Cox M, Tripp J, Blacksell S. Clinical performance of the levonorgestrel intrauterine system in routine use by the UK Family Planning and Reproductive Health Research Network: 5-year report. J Fam Plann Reprod Health Care 2002;28:73-7.

5. American Congress of Obstetricians and Gynecologists Committee on Gynecologic Practice; LongActing Reversible Contraception Working Group. ACOG Committee Opinion no. 450: increasing use of contraceptive implants and intrauterine devices to reduce unintended pregnancy. Obstet Gynecol 2009; 114:1434-8.

6. Delbanco TL, Daley J. Through the patient's eyes: strategies toward more successful contraception. Obstet Gynecol 1996;88(3 Suppl):41S-7S.

7. HealthCare.gov. Birth control benefits. Available from: http://www.healthcare.gov/coverage/birth-controlbenefits/. Accessed February 5, 2015.

8. Tugrul S, Yavuzer B, Yildirim G, Kayahan A. The duration of use, causes of discontinuation, and problems during removal in women admitted for removal of IUD. Contraception 2005;71:149-52.

9. Cea-Soriano L, Garcia Rodriguez LA, Machlitt A, Wallander MA. Use of prescription contraceptive methods in the UK general population: a primary care study. BJOG 2014;121:53-60, discussion 60-1.

10. Dickerson LM, Diaz VA, Jordon J, et al. Satisfaction, early removal, and side effects associated with longacting reversible contraception. Fam Med 2013;45: 701-7.

11. Werth SR, Secura GM, Broughton HO, Jones ME, Dickey V, Peipert JF. Contraceptive continuation in Hispanic women. Am J Obstet Gynecol 2015;212: 312.e1-8. 
12. Dehlendorf C, Diedrich J, Drey E, Postone A, Steinauer J. Preferences for decision-making about contraception and general health care among reproductive age women at an abortion clinic. Patient Educ Couns 2010;81:343-8.

13. Dehlendorf C, Kimport K, Levy K, Steinauer J. A qualitative analysis of approaches to contraceptive counseling. Perspect Sex Reprod Health 2014;46: 233-40.

14. Alnakash AH. Influence of IUD perceptions on method discontinuation. Contraception 2008;78: 290-3.

15. Dehlendorf C, Tharayil M, Anderson N, Gbenedio K, Wittman A, Steinauer J. Counseling about IUDs: a mixed-methods analysis. Perspect Sex Reprod Health 2014;46:133-40.
16. O'Neil-Callahan M, Peipert JF, Zhao Q, Madden T, Secura G. Twenty-four-month continuation of reversible contraception. Obstet Gynecol 2013;122: 1083-91.

17. Madden T, Mullersman JL, Omvig KJ, Secura GM, Peipert JF. Structured contraceptive counseling provided by the Contraceptive CHOICE Project. Contraception 2013;88:243-9.

18. Halpern V, Lopez LM, Grimes DA, Stockton LL, Gallo MF. Strategies to improve adherence and acceptability of hormonal methods of contraception. Cochrane Database Syst Rev 2013;10:CD004317.

19. Anderson N, Steinauer J, Valente T, Koblentz J, Dehlendorf C. Women's social communication about IUDs: a qualitative analysis. Perspect Sex Reprod Health 2014;46:141-8. 